\title{
INDIGENOUS PROPERTY MATTERS IN REAL PROPERTY COURSES AT AUSTRALIAN UNIVERSITIES
}

\author{
Nicole Graham*
}

\section{INTRODUCTION}

The approach to the teaching of property law varies significantly across and within Australian universities. 'This may be attributed to the 'challenging', 'problematic' and 'difficult' nature of legal education in general, which attempts to 'satisfy simultaneously the immediate demands of legal practice and the traditional values associated with the university ${ }^{2}{ }^{2}$ The disparity of purpose apparent in this dual commitment accounts for a degree of contrast between approaches to teaching Indigenous-Australian land laws; Indigenous perspectives on Anglo-Australian property laws; and the law of native title. A minority of real property courses include any or all of these topics to a significant degree in their content, materials and assessment. However, many real property courses adopt a conventional model of legal education that emphasises the immediate practical function of doctrinal knowledge to, and for, a predominantly non-Indigenous property market. ${ }^{3}$ This paper contends that the use of the conventional model of legal education in teaching real property often coincides with an exclusion of Indigenous-Australian land laws and perspectives on Anglo-Australian property law and sometimes even an exclusion of the Anglo-Australian law of native title. Where Indigenous laws and perspectives are presented in real property courses, they are often referred to via abstract technical or 'substantive' aspects of native

* Senior Lecturer, Faculty of Law, University of Technology, Sydney.

${ }^{1}$ Lynden Griggs and Rick Snell, "The Curriculum and Teaching of Property Law in Australian Law Schools' (1997) 5 Australian Property Law Journal 213.

${ }^{2}$ Margaret Thornton, 'Portia Lost in the Groves of Academe Wondering What to do about Legal Education (Inaugural Lecture, Department of Legal Studies, La Trobe University, 1991) I.

3 The information on real property course curricula is based on research that appears in ch 5, pt 4 'Dephysicalised Property in Pedagogic Practice' in Nicole Graham, Lawscape: Paradigm and Place in Australian Property Law (PhD Thesis, University of Sydney, 2003); on the content and structure of several current leading texts on real property law in Australia and NSW, around which many courses in NSW law schools are structured; and on informal discussions with property teachers. 


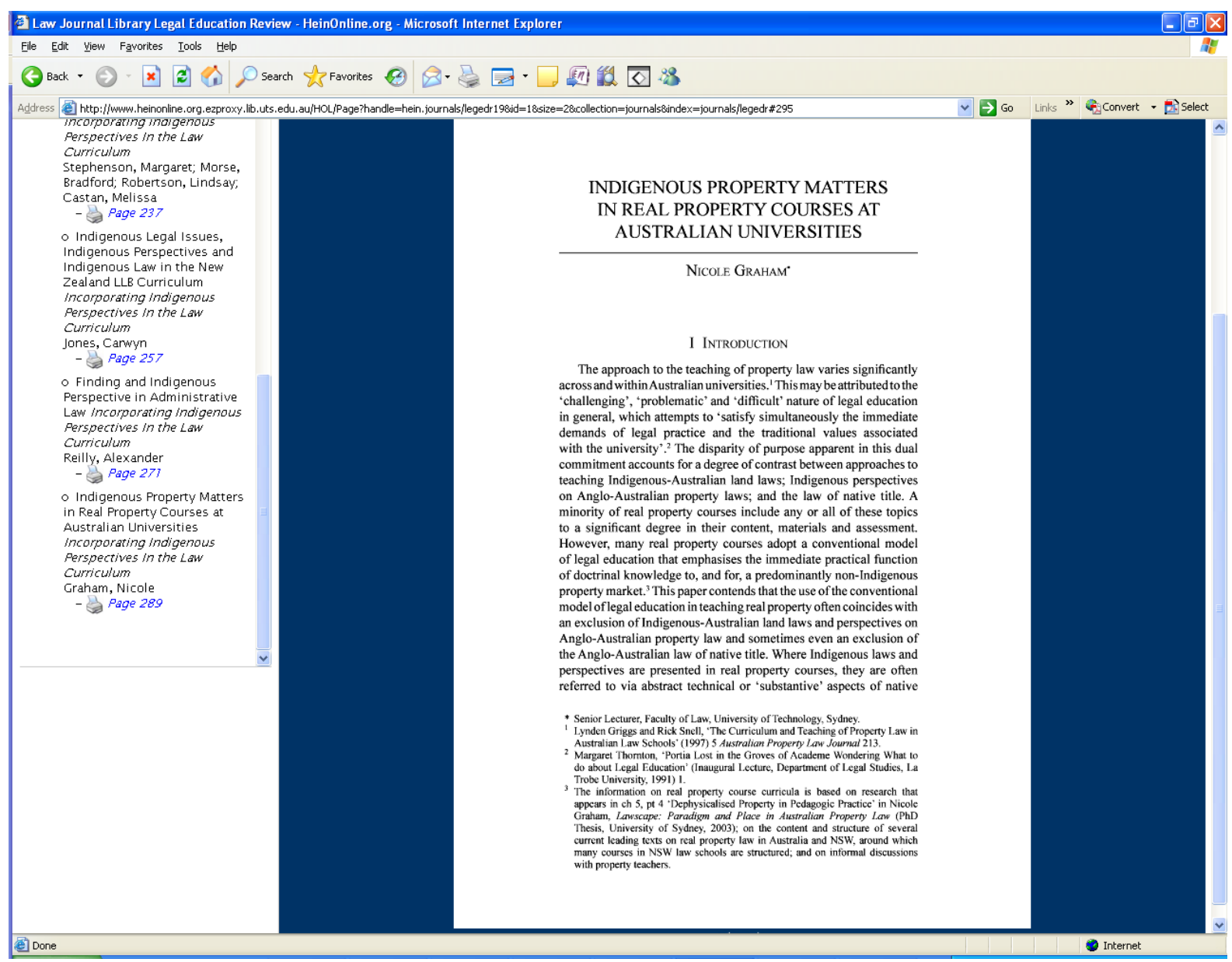




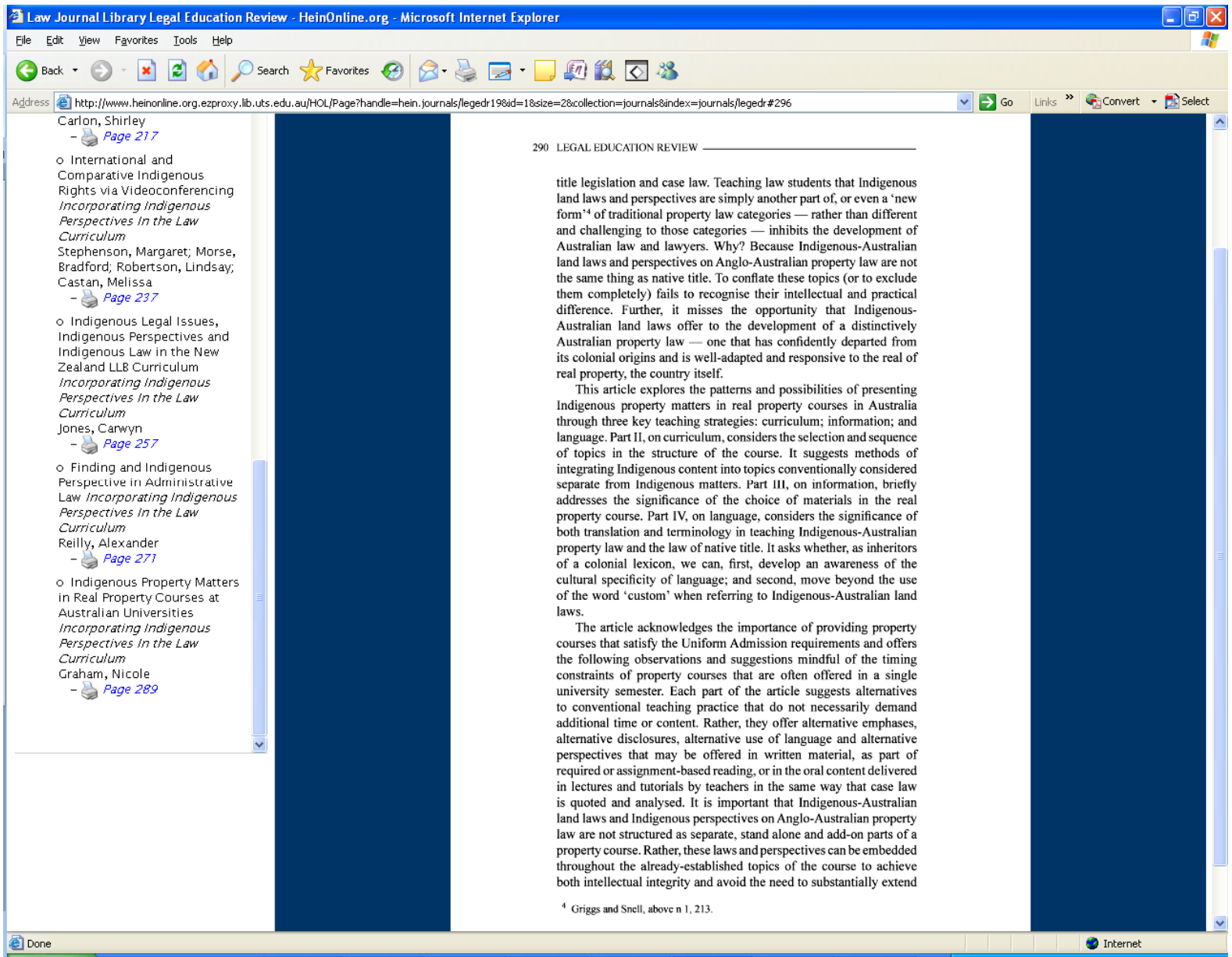




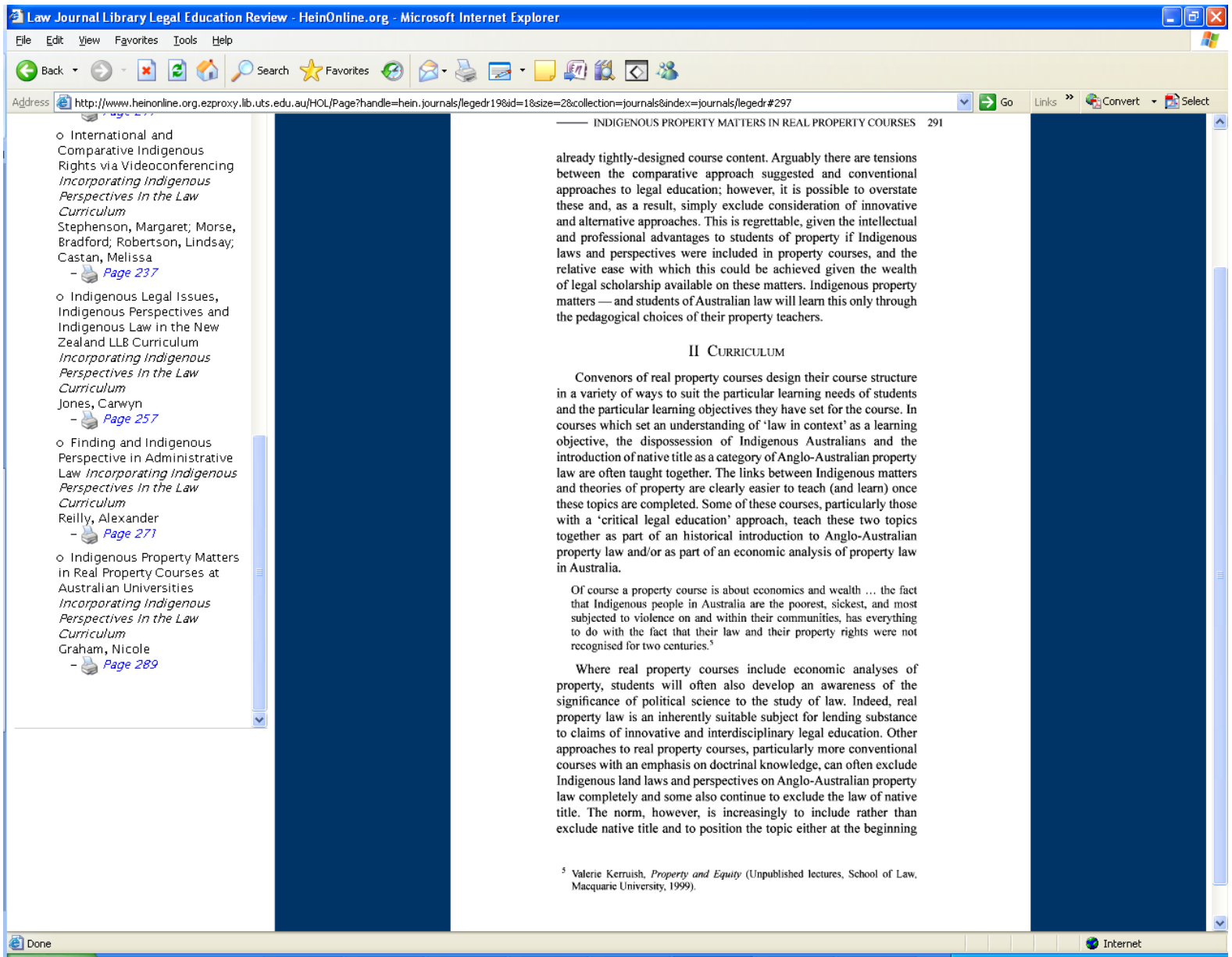




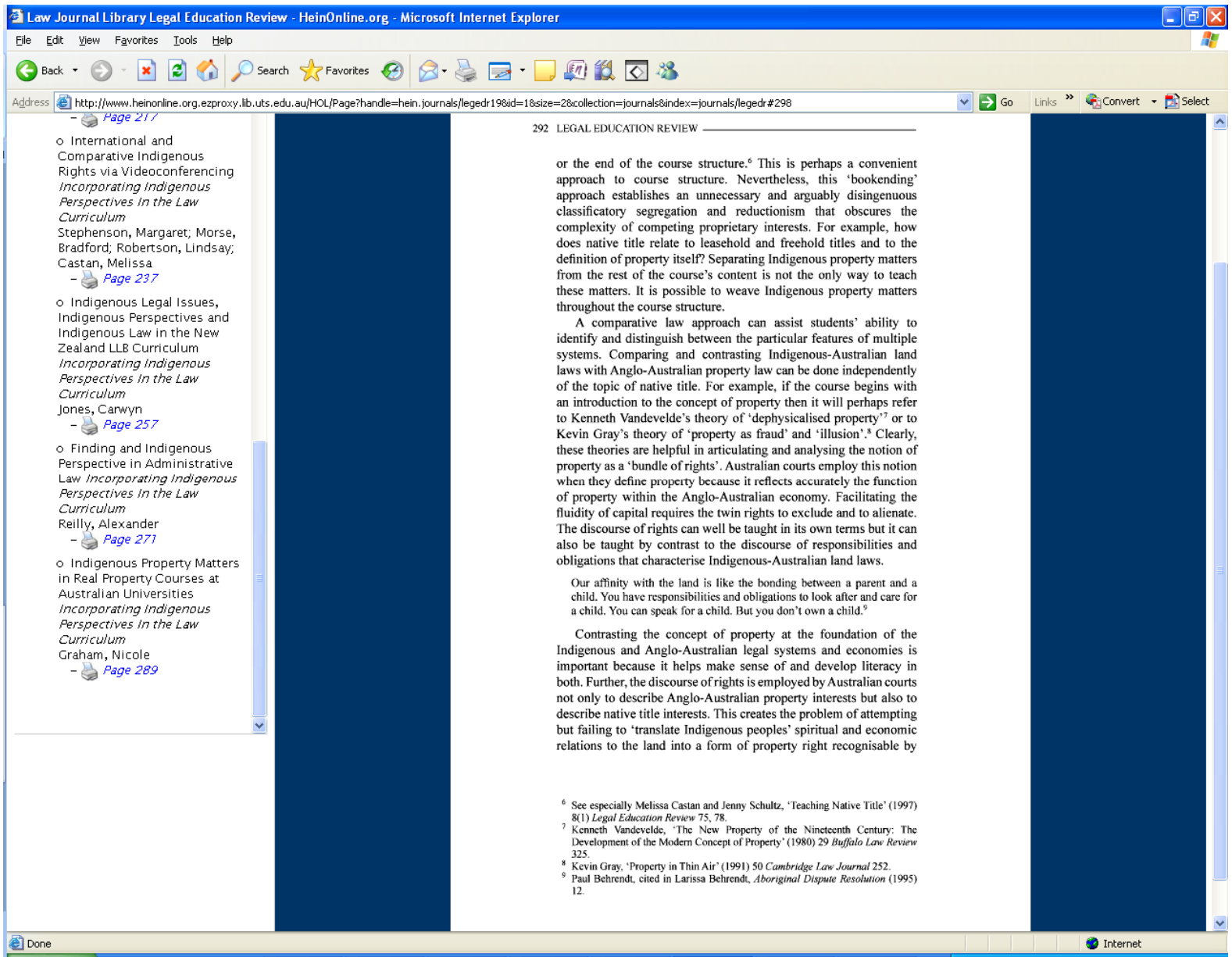




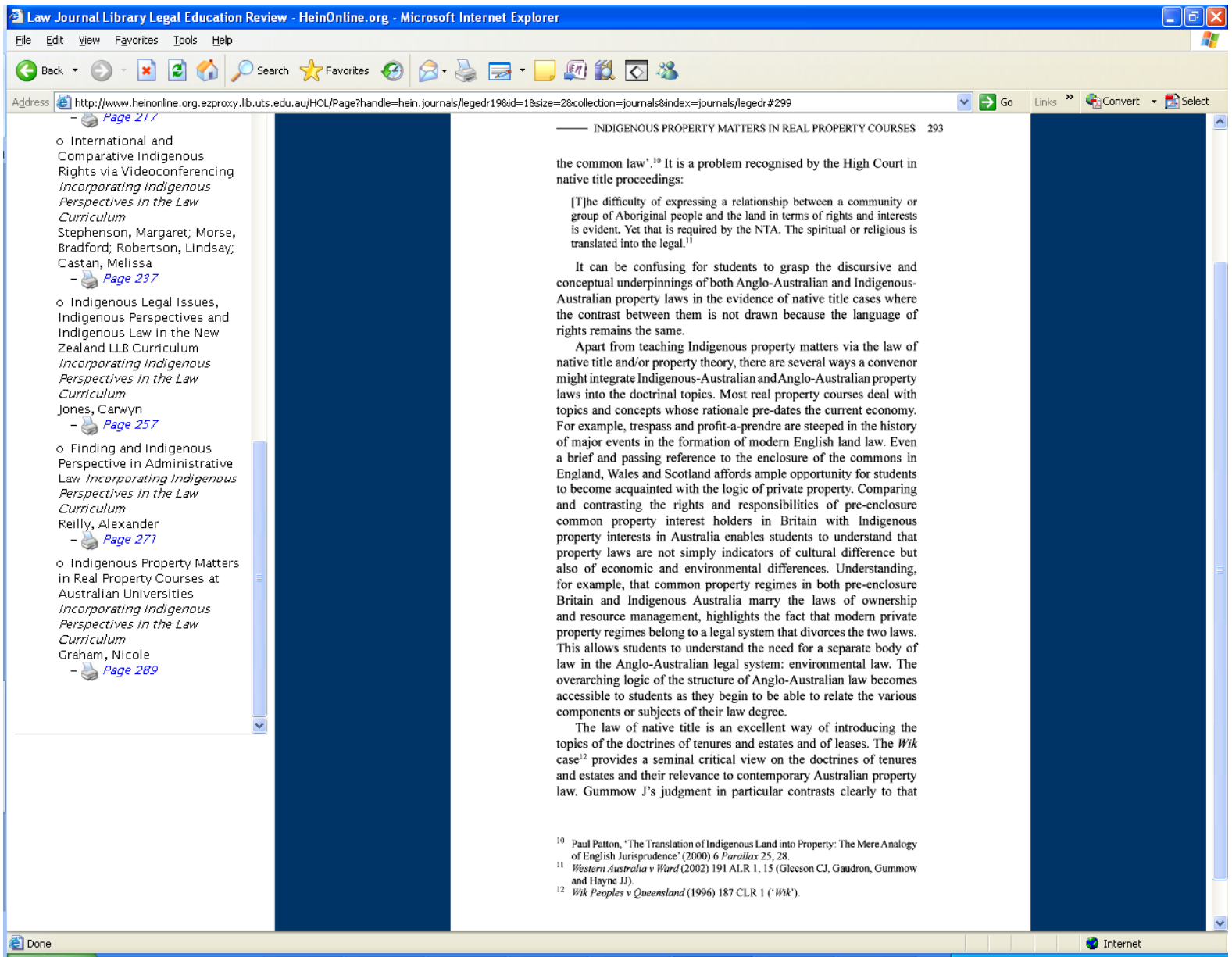




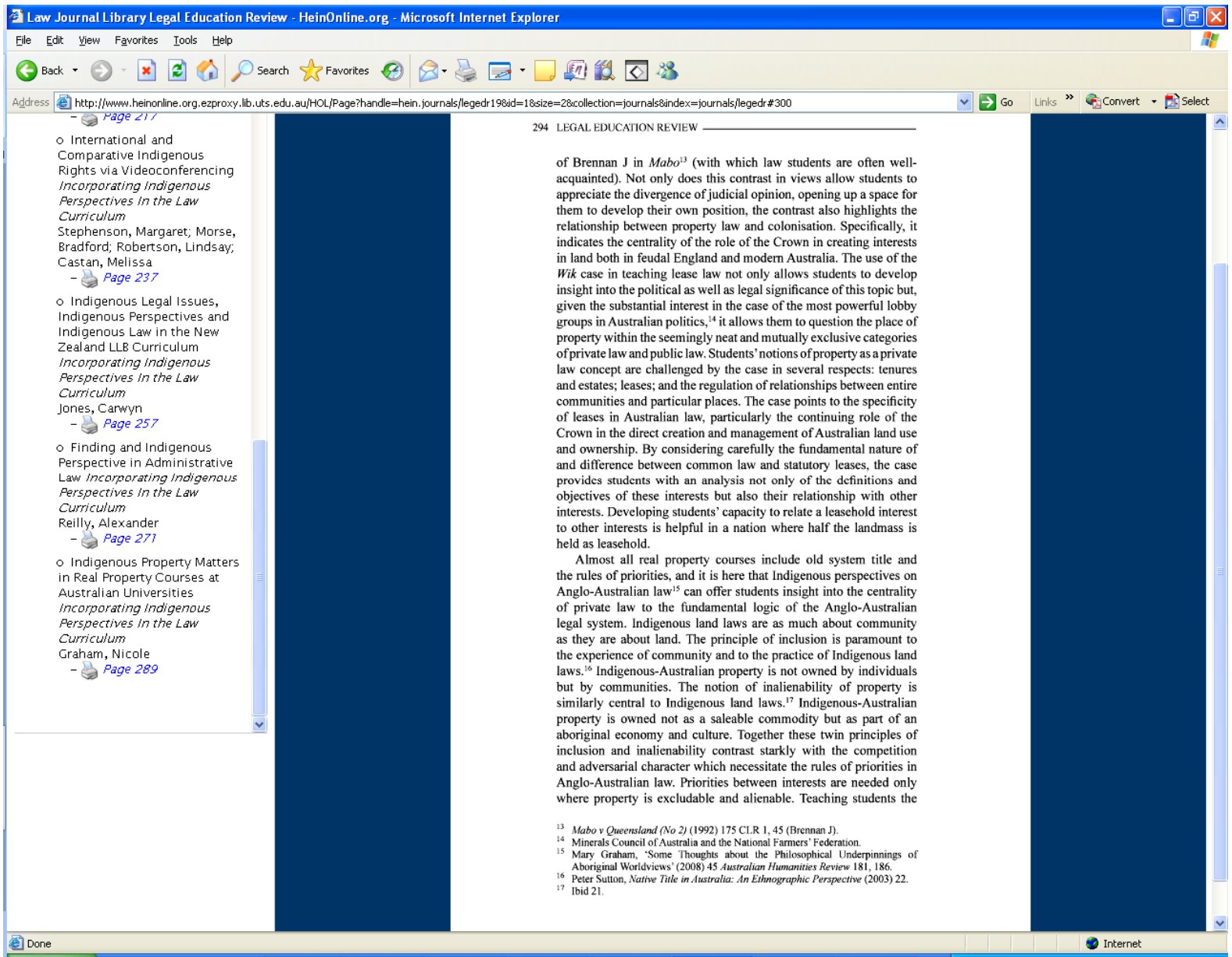




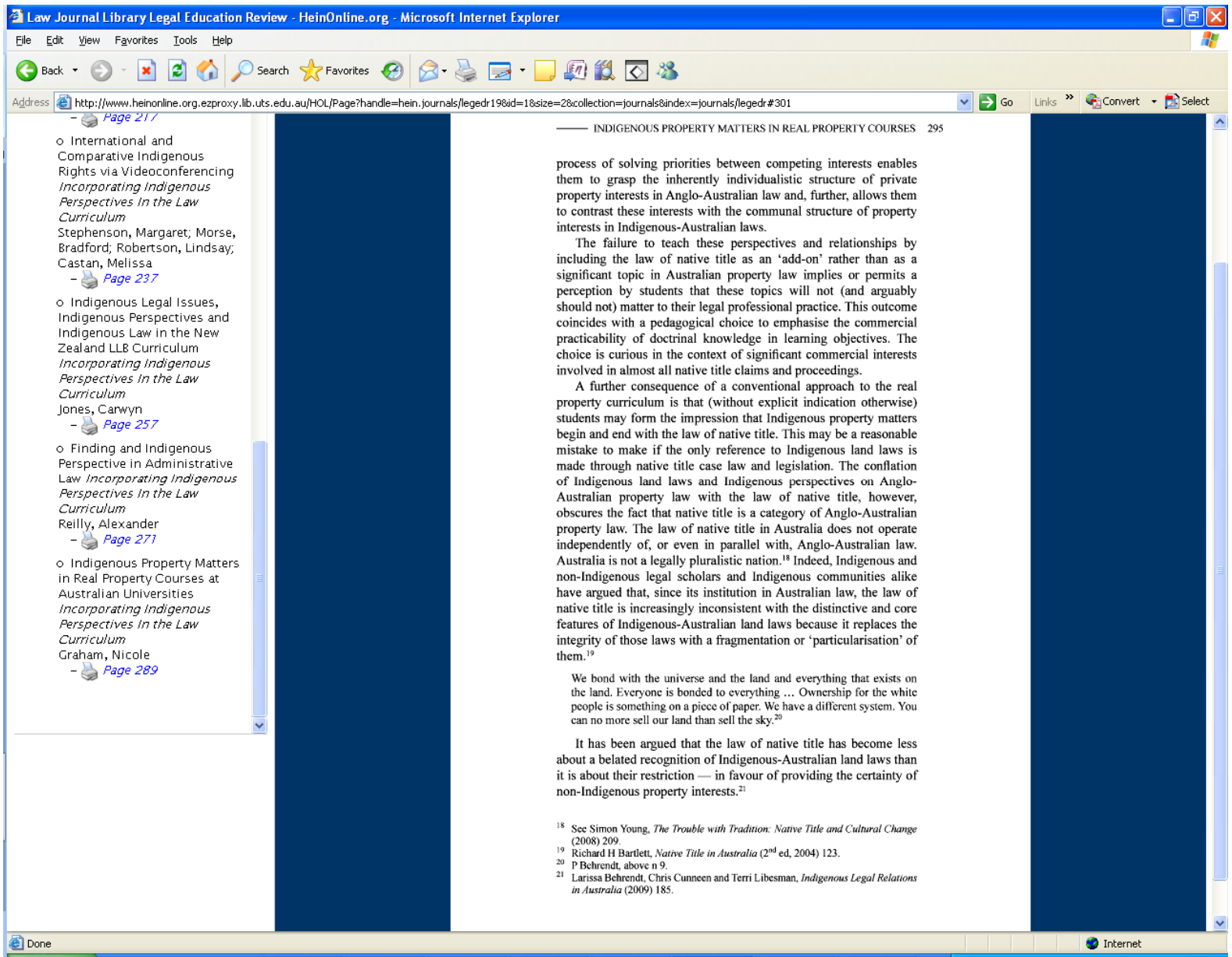




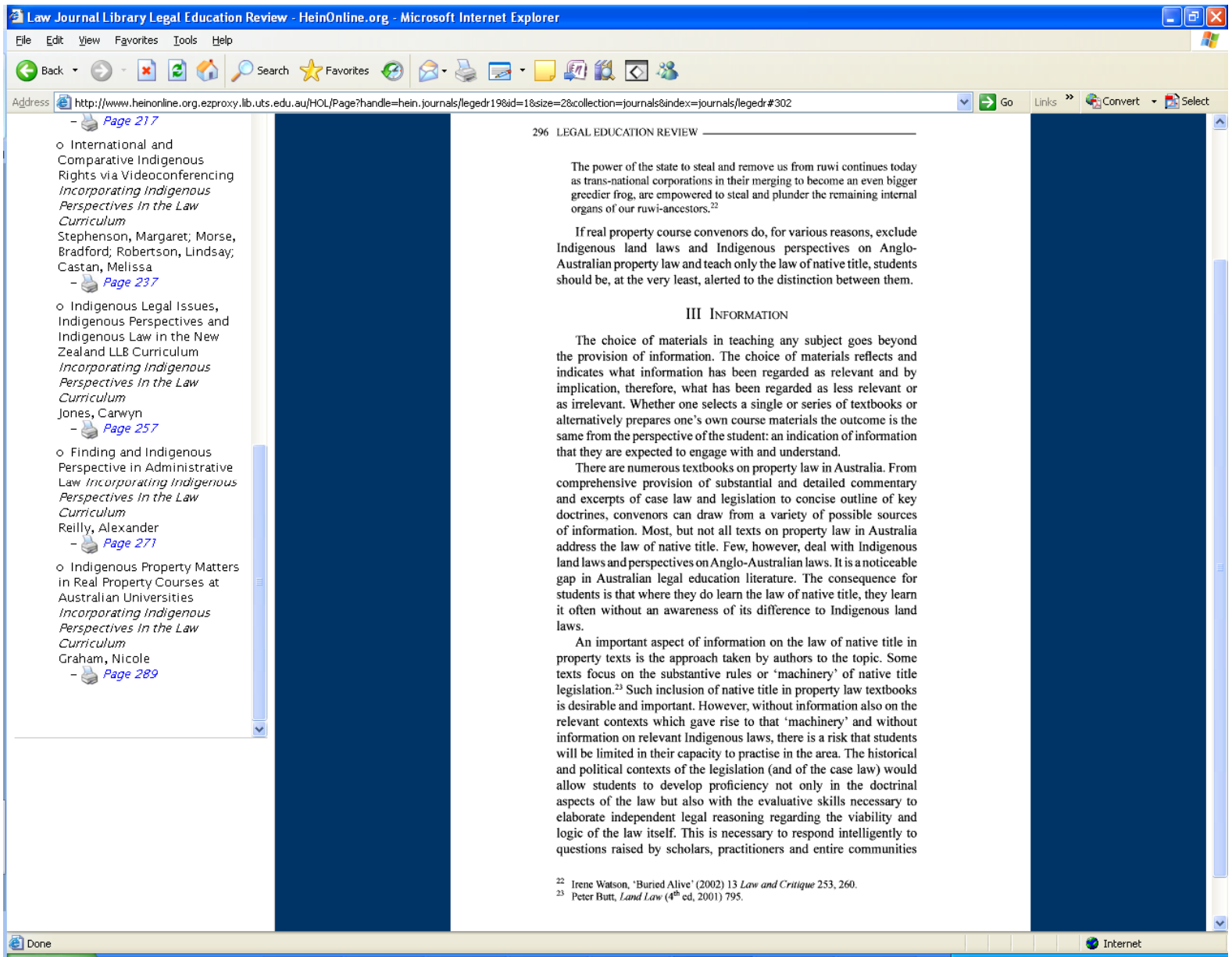




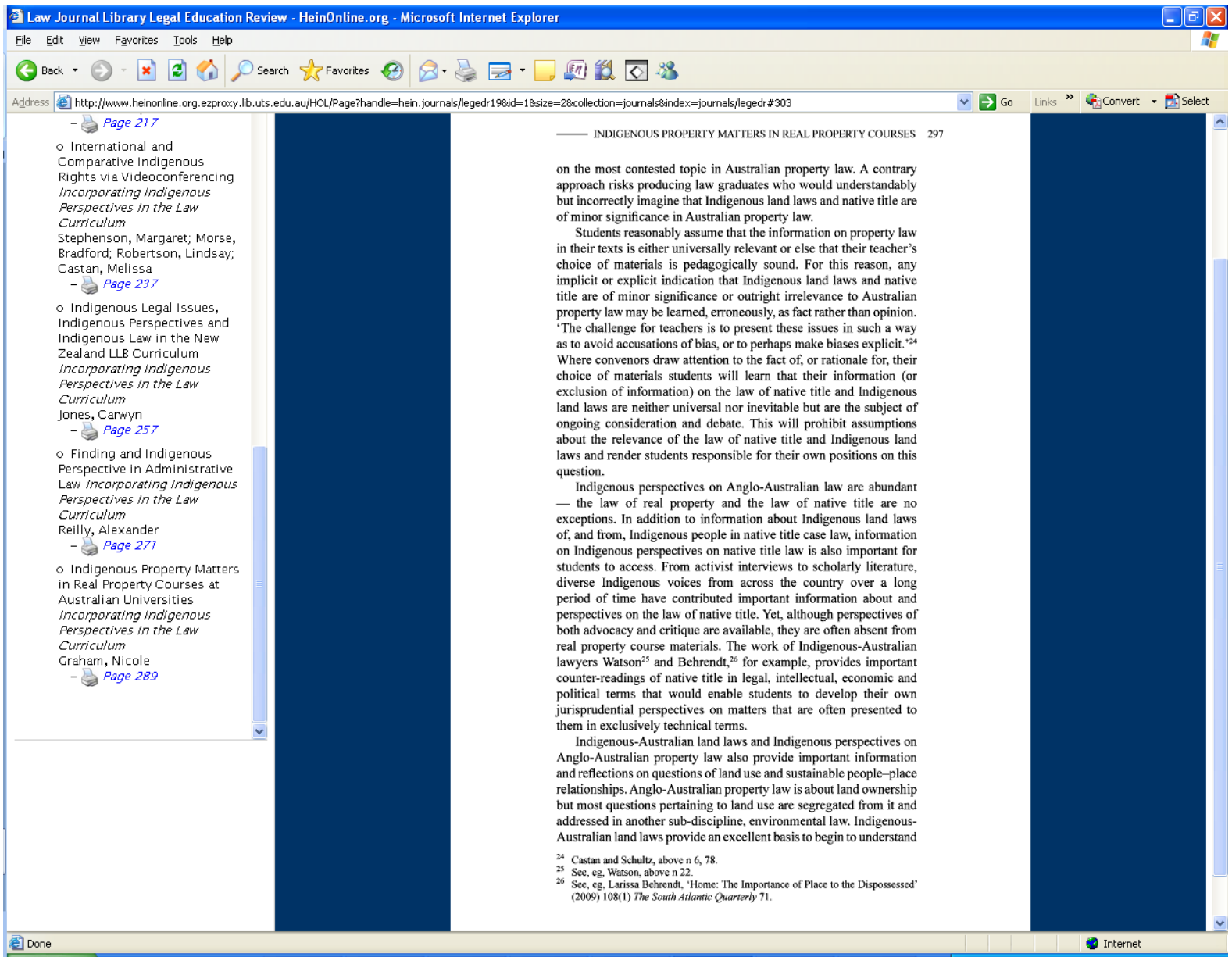




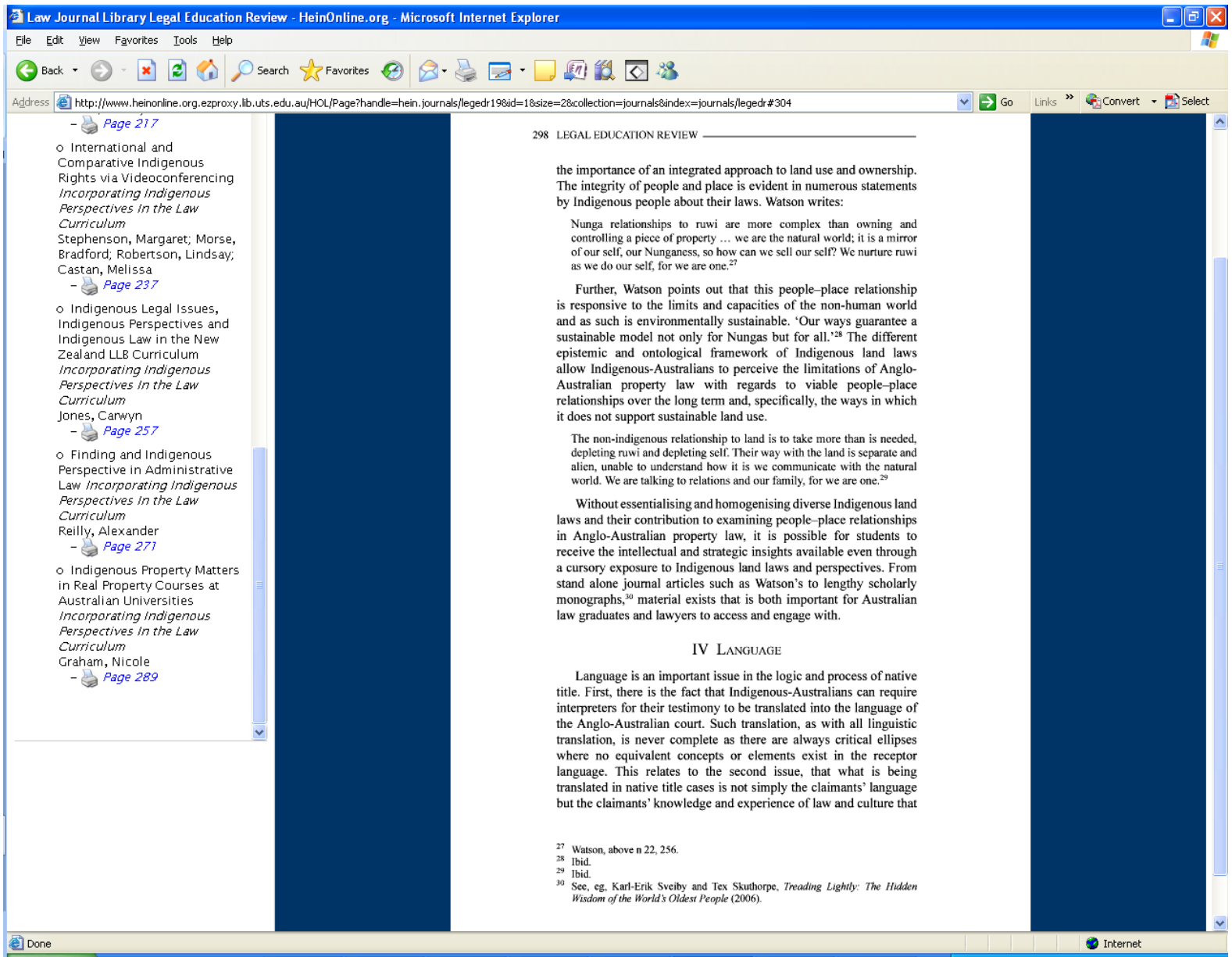




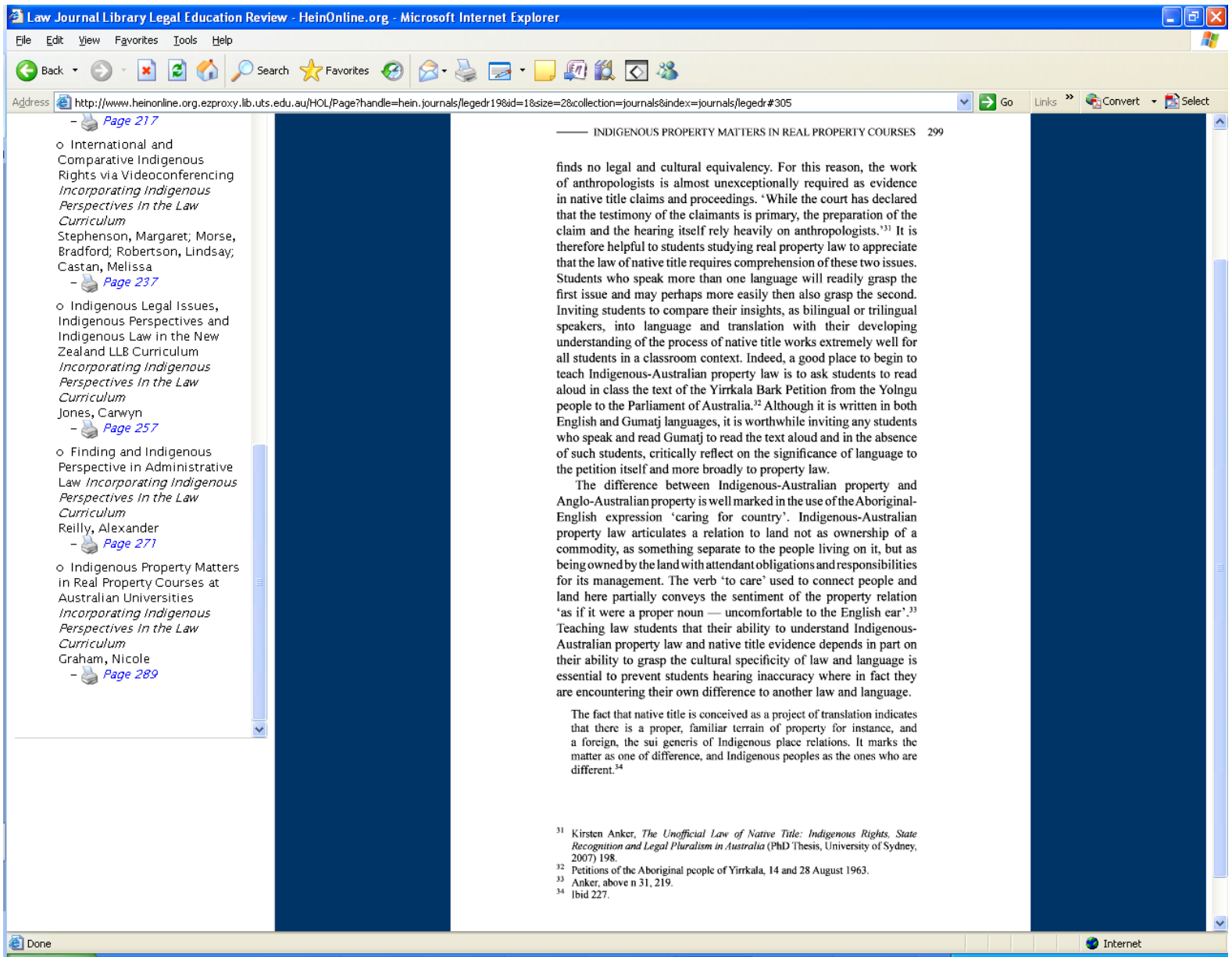




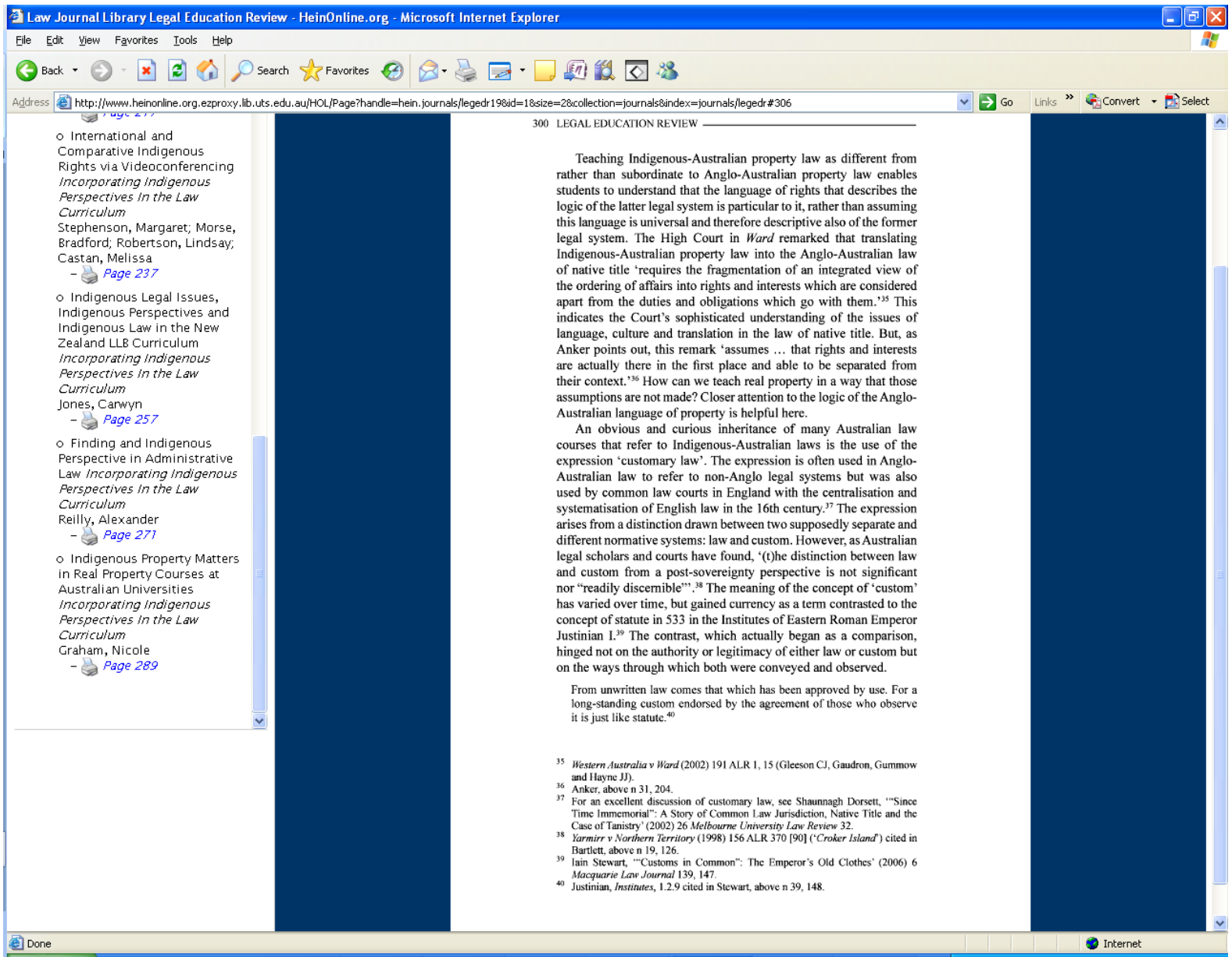




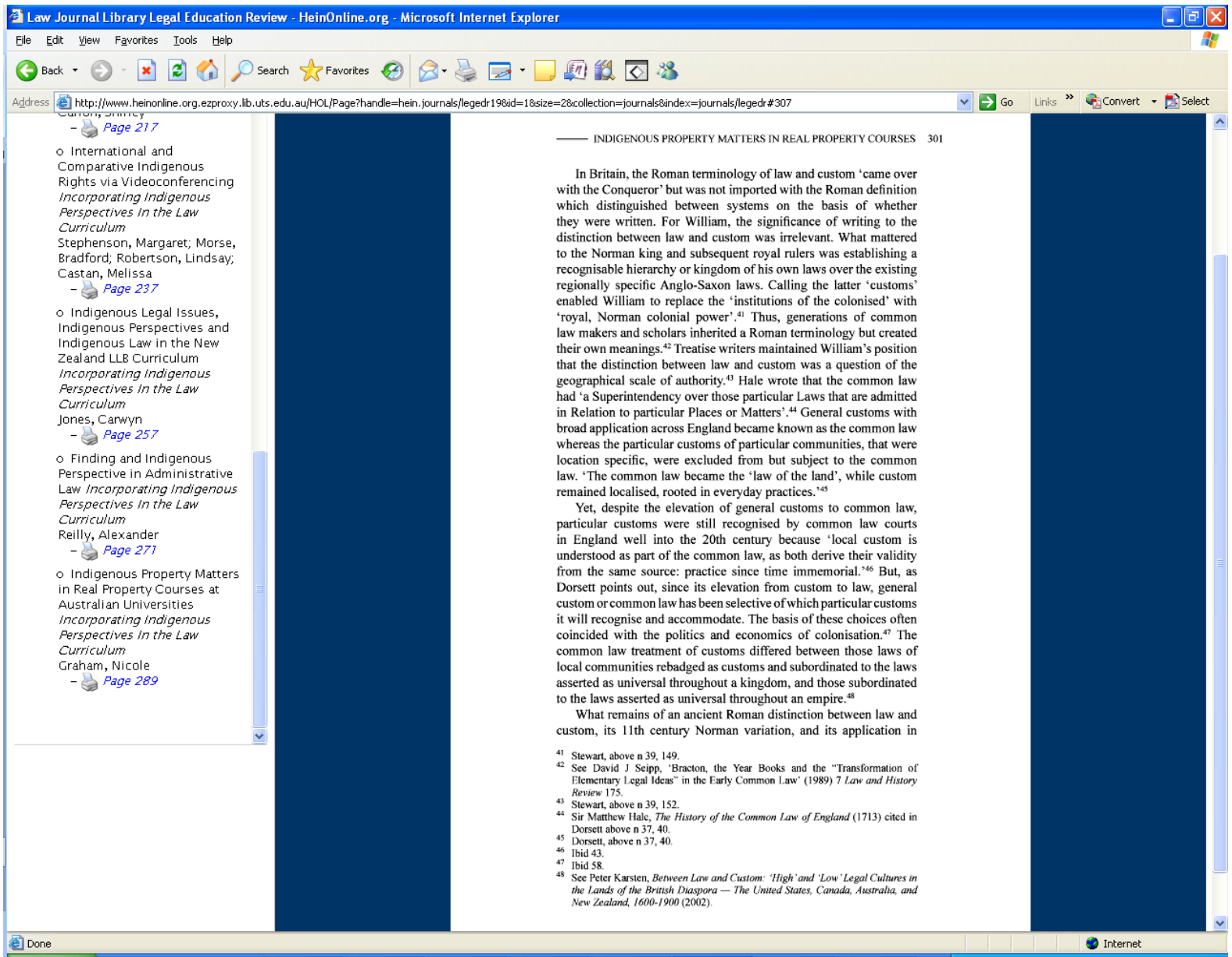




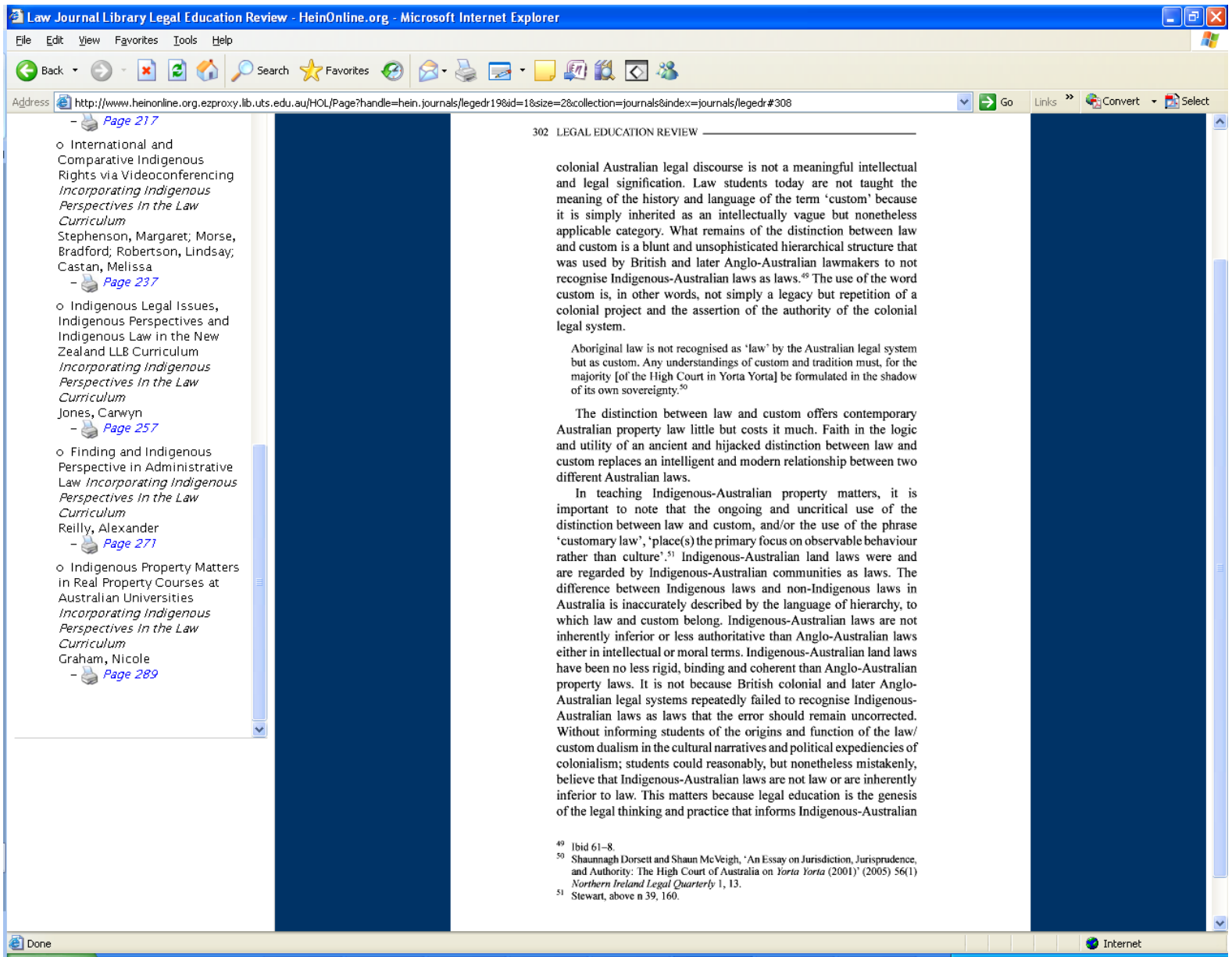




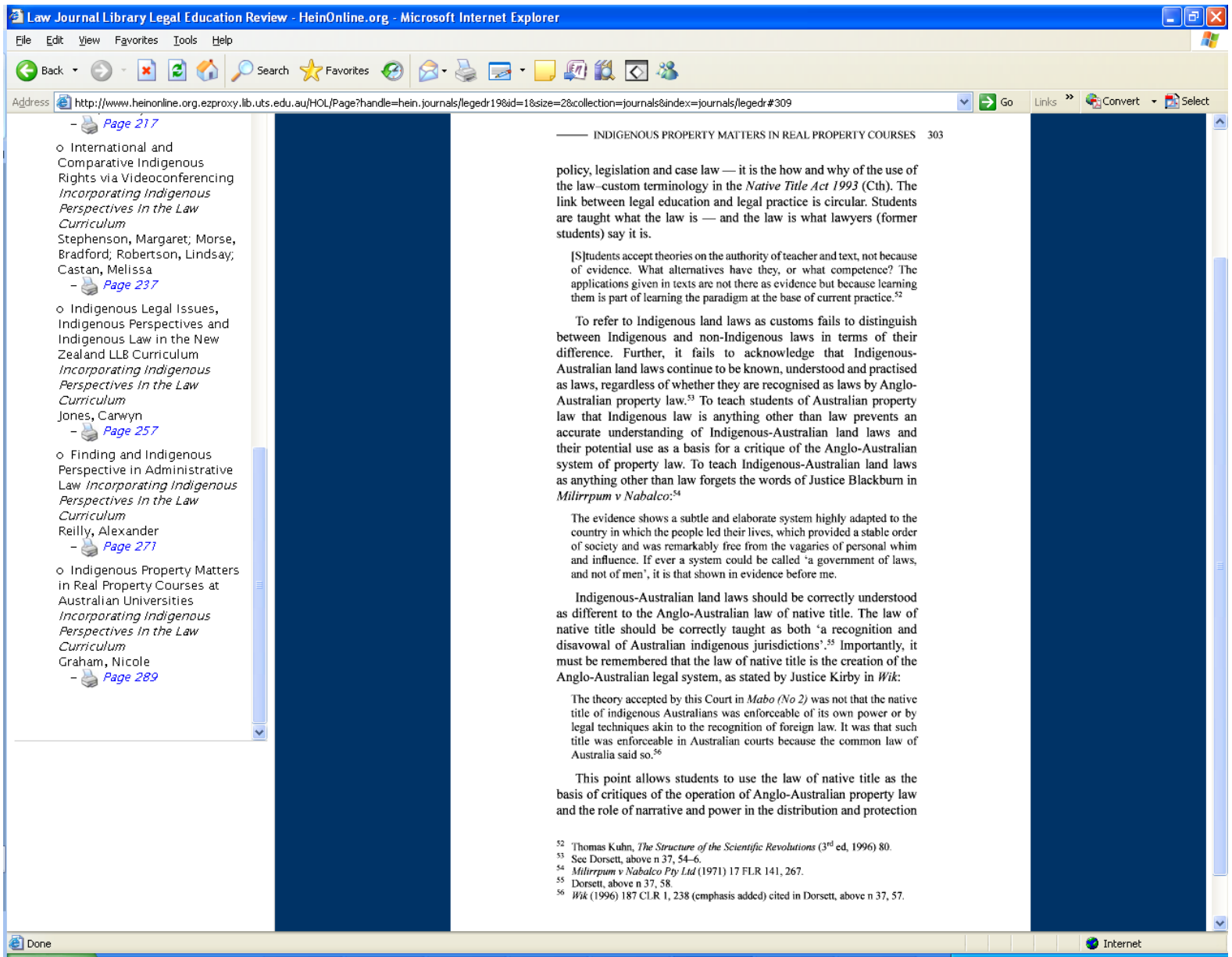


- International an

Page 28 